\title{
Low sensitivity of counter-current immuno- electrophoresis for serodiagnosis of typhoid fever
}

\author{
MEERA SHARMA, USHA DATTA, PALLAB ROY*, S. VERMA $\dagger$ and SHOBHA SEHGAL \\ Departments of Immunopathology, * Microbiology and $\dagger$ Internal Medicine, Postgraduate Institute of Medical \\ Education and Research, Chandigarh-160012, India
}

\begin{abstract}
Counter-current immuno-electrophoresis was evaluated as a diagnostic test for the serodiagnosis of typhoid fever with somatic (O), flagellar (H) and capsular polysaccharide (Vi) antigens of Salmonella typhi on the sera of patients who were blood culture positive (confirmed typhoid cases) or had high Widal agglutination titres, $\geqslant 320$, (presumptive typhoid cases). Of the 37 sera from confirmed cases, $30 \%$ showed positivity with $\mathrm{O}$ antigen, $24 \%$ with $\mathrm{H}$ antigens and $51 \%$ with $\mathrm{Vi}$ antigen. In patients with a presumptive diagnosis, $45 \%$ were positive for $O$ antibody, $27 \%$ for flagellar antibody and $52 \%$ for $V i$ antibody. When all three antigens were combined the reactivity to any of the antigens was found to be $59 \%$ in confirmed typhoid cases, $\mathbf{7 9 \%}$ in presumptive typhoid cases and $93 \%$ in patients who were simultaneously positive by blood culture and Widal agglutination. However, none of the sera from 45 controls gave a positive precipitation reaction with any of the antigens. It is concluded that countercurrent immuno-electrophoresis is a rapid test with low sensitivity and high specificity with Vi antigen, a panel of antigens being most effective, and is, therefore, recommended for rapid diagnosis of typhoid fever.
\end{abstract}

\section{Introduction}

Typhoid fever is still one of the major unsolved health problems with an estimated world-wide incidence of $c$. 12.5 million cases annually, with $>62 \%$ of these occurring in Asia [1].

Laboratory confirmation of a clinical diagnosis of typhoid fever depends essentially on bacterial culture. This has drawbacks, as during the first week of fever, $20 \%$ of patients may be culture negative and the positivity declines further with time [2]. Serological diagnosis by Widal agglutination test is also unreliable, as demonstration of rising titres is essential [3]. In India, most patients present late to hospital and require immediate diagnosis and treatment. Therefore, it is essential to develop better methods for rapid diagnosis.

The present work was done to evaluate the usefulness of counter-current immuno-electrophoresis for detecting antibodies to somatic $(\mathrm{O})$, flagellar $(\mathrm{H})$ and capsular polysaccharide (Vi) antigens of Salmonella typhi in patients who were diagnosed as definite or

Received 13 Aug. 1996; revised version received 4 April 1997; accepted 1 May 1997.

Corresponding author: Dr U. Datta. probable cases of typhoid on the basis of blood culture positivity and Widal agglutination, respectively.

\section{Materials and methods}

\section{Patients}

Sixty-six patients clinically diagnosed as having typhoid fever on the basis of fever, diarrhoea, abdominal pain, with or without perforation, were confirmed by positive blood culture for $S$. typhi or high titres $(\geqslant 320$ ) of Widal agglutination, or both. Blood culture positive and Widal positive patients were grouped into group 1 and group 2, respectively. Group 3 comprised patients who were simultaneously positive by blood culture and Widal agglutination. Forty-five healthy individuals with Widal agglutination titres $<80$ and who were blood culture negative for $S$. typhi served as controls.

\section{Antigens for counter-current immuno- electrophoresis}

$O$ antigen. A centrifuged ultrasonic lysate of $S$. typhi O901 strain was used as antigen as advocated by Gupta and Rao [4].

$H$ antigen. Motile $S$. typhi of strain H901 was grown in brain heart infusion broth. Flagellar $(\mathrm{H})$ antigen 
was prepared according to the method of Ibrahim et al. [5].

Vi antigen. The modified method of Ewing [6] was followed to prepare the $\mathrm{Vi}$ antigen from a clinical isolate of $S$. typhi showing agglutination with commercially available $\mathrm{Vi}$ antisera. The antigen was prepared by removing the growth of a pure Vi positive $S$. typhi culture from MacConkey agar plates. It was then suspended in absolute alcohol. The bacteria were dehydrated in vacuo and resuspended in physiological saline. The suspension was sonicated 10 times at 20 kilocycles with bursts of $45 \mathrm{~s}$ each at 1-min intervals in an MSE sonicator. The sonicated fraction was used as antigen for counter-current immuno-electrophoresis.

\section{Raising hyperimmune antisera}

Antisera to $\mathrm{O}, \mathrm{H}$ and $\mathrm{Vi}$ antigens were raised in 6-8month-old New Zealand White rabbits as described by Ewing [6].

\section{Counter-current immuno-electrophoresis}

Counter-current immuno-electrophoresis was performed according to the method of Ouchterlony and Nilsson [7] with some modifications. The slides were prepared with noble agar $0.9 \%$ dissolved in $0.05 \mathrm{M}$ barbitone buffer $(\mathrm{pH} 8.6)$. The antigens $(\mathrm{O}, \mathrm{H}$ and $\mathrm{Vi}$ antigens of $S$. typhi) were placed in the cathodal wells and patients' sera diluted (1 in 200) in phosphatebuffered saline $(0.02 \mathrm{M}, \mathrm{pH} 7.4)$ in the anodal wells. A constant current was applied along the slide for $45 \mathrm{~min}$ at a rate of $5-6 \mathrm{~mA} / \mathrm{cm}$. The samples showing the characteristic precipitation line were interpreted as positive. Antisera raised in rabbits served as positive controls. Normal rabbit serum was also included to eliminate false positive reactions for $S$. typhi.

\section{Widal agglutination}

The method given by Gupta and Rao [4] was followed for conducting the Widal agglutination test.

\section{Results}

In group 1, blood culture was positive in 37 of 66 patients over a variable time after the onset of fever as shown in Table 1 . Peak blood culture positivity (40\%) was found in the second week of fever. However, 19\% continued to be positive for up to nearly 1 month. In group 2, 34\% were Widal positive in the second as well as the third week. Group 3, where both blood culture and Widal agglutination were simultaneously positive, comprised 15 patients, of whom $40 \%$ were positive in the second week of fever.

The rates of detection of antibodies by counter-current immuno-electrophoresis with three different antigens are shown in Fig. 1. Eleven $(30 \%)$ of 37 patients of the blood culture positive group reacted with somatic $O$ antigen. On the other hand, 13 (45\%) of 29 patients in the second group were positive for $O$ antibody. Positivity with $\mathrm{O}$ antigen was found in four samples from the third group.

Flagellar $\mathrm{H}$ antigen yielded precipitation lines in only nine $(24 \%)$ of 37 patients with confirmed typhoid fever. Eight $(27 \%)$ of 29 patients of the second group were positive for flagellar antibody by counter-current immuno-electrophoresis. Only two cases in group 3 were positive with $\mathrm{H}$ antigen.

Antibodies to Vi antigen were detected in $19(51 \%)$ of 37 patients of the first group. In the second group 15 $(52 \%)$ of 29 patients were positive for $\mathrm{Vi}$ antibody. However, this antigen gave a positive reaction with 12 sera from patients in the third group. When all three

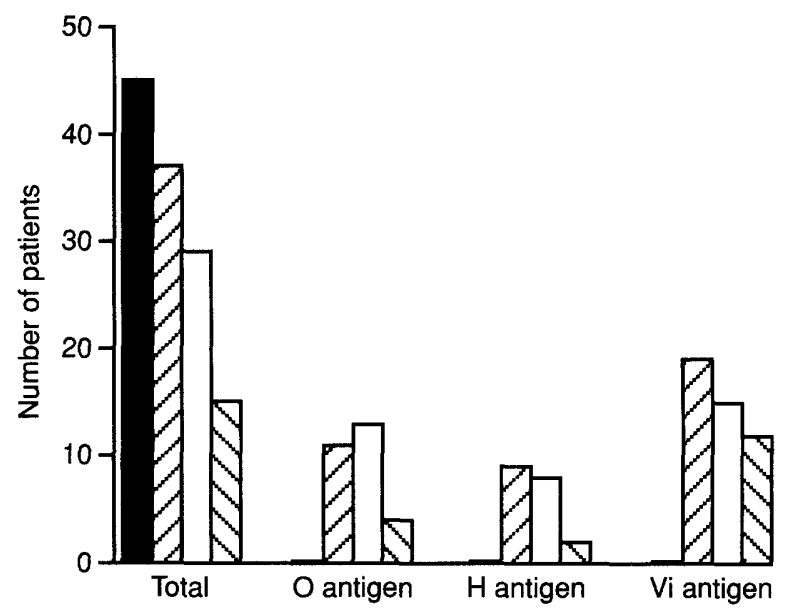

Fig. 1. Detection of antibodies to $\mathrm{O}, \mathrm{H}$ and $\mathrm{Vi}$ antigens by counter-current immuno-electrophoresis in patients with typhoid: $\square$ controls; $\square$ blood-culture positive; $\square$ Widal positive; $\mathbf{\Omega}$ blood-culture positive and Widal positive.

Table 1. Diagnosis of typhoid fever by blood culture and Widal agglutination over a variable period of infection

\begin{tabular}{|c|c|c|c|c|c|}
\hline \multirow[b]{2}{*}{ Method } & \multirow[b]{2}{*}{$\begin{array}{l}\text { Total number of } \\
\text { cases }\end{array}$} & \multicolumn{4}{|c|}{ Number ( $\%$ of total cases) of patients with fever for } \\
\hline & & $\begin{array}{l}0-7 \text { days } \\
(1 \text { st week })\end{array}$ & $\begin{array}{l}8-14 \text { days } \\
\text { (2nd week) }\end{array}$ & $\begin{array}{l}15-12 \text { days } \\
\text { (3rd week) }\end{array}$ & $\begin{array}{l}22-28 \text { days } \\
\text { (4th week) }\end{array}$ \\
\hline Blood culture positive & 37 & $7(19 \%)$ & $15(40 \%)$ & $8(22 \%)$ & $7(20 \%)$ \\
\hline Widal positive & 29 & $5(17 \%)$ & $10(34 \%)$ & $10(34 \%)$ & $4(14 \%)$ \\
\hline $\begin{array}{l}\text { Both (blood culture positive } \\
\text { and Widal positive) }\end{array}$ & 15 & $2(13 \%)$ & $6(40 \%)$ & $5(33 \%)$ & $2(13 \%)$ \\
\hline
\end{tabular}


antigens were considered together as a panel and the positivity rates to at least one of the antigens measured, group 1 showed positivity of $59 \%$ and group $279 \%$; however, group 3 showed a positivity rate of $93 \%$

\section{Discussion}

Typhoid fever continues to be a major endemic disease in India [8]. Patients presenting with fever and signs raising high clinical suspicion require early diagnosis with tests that should be specific, sensitive, inexpensive and rapid. The two main tests that are routinely done at present are blood culture and Widal reaction; neither of these tests fulfils all the above criteria.

Isolation of $S$. typhi from blood culture remains the gold standard, but requires at least $48 \mathrm{~h}$ for confirmation. Parker [9] reviewed studies conducted in the preantibiotic era and reported blood culture positivity in $90 \%$ of cases in the first week of illness, which declined to $70 \%$ in the second week. By the end of the third week it was positive in $45 \%$ of cases. After the fourth week the isolation of $S$. typhi from the blood of a patient was infrequent. Similarly, Stuart and Pullen [2] reported $80 \%$ positivity in the first week which declined to $30 \%$ by the end of the third week of illness. The incidence of positive isolation varied greatly in recent studies, ranging from $48 \%$ to $75 \%$ [10]. It is documented that culture may be negative in the presence of low grade bacteraemia [10] possibly because the bacteria are intracellular in the mononuclear cells of the blood and inhibitory serum factors such as antibodies or complement, may be present. Fifty-six percent of the patients in the present study were positive by blood culture, which is comparable with the earlier reports. However, positivity was found to be highest $(40 \%)$ in the second week after the onset of fever and $19 \%$ of patients were positive up to the fourth week of fever.

The second most widely used test is the agglutination reaction popularly known as the Widal test. The serum of a proportion of patients in endemic countries contains antibodies capable of reacting to a variable titre in the Widal test, but usually the titres are low [9]. Even those individuals vaccinated with typhoidparatyphoid (TAB) vaccine show $\mathrm{H}$ antibodies for a long period. Reactions to $\mathrm{H}$ antigens are more reliable than those to $O$ antigen. The value of the Widal agglutination test for the serological diagnosis of Salmonella infection is often questioned [11]. Akoh [12] reported $44 \%$ Widal positivity, whereas Duthie and French [13] showed $75.5 \%$ positivity by Widal agglutination. In the present study only $40 \%$ of the blood culture-confirmed typhoid patients gave positive agglutination reactions with a titre of 320 or more in the second week of infection, $33 \%$ of those in the third week of infection, but only $13 \%$ were positive by agglutination in the first and fourth week of fever.
Demonstration of rising titres is recommended for the Widal test. However, often a single test has to be relied on for the diagnosis of typhoid. The present study included a group of patients who were blood culture negative but had high titres $(\geqslant 320)$ of Widal positivity; these were considered presumptive typhoid cases. It has also been reported that culture positive cases may be Widal negative throughout the illness. The Widal test is considered to have low specificity and low sensitivity and this was corroborated by the present study.

The study by Gupta and Rao [4] established countercurrent immuno-electrophoresis as a highly specific test with no false positive results. They used an ultrasonic lysate of $S$. typhi strain 0901 as antigen and could detect antibody to this antigen in all the convalescent cases of typhoid fever, whereas only one of 26 acute typhoid cases gave a positive reaction. On the other hand, Sundararaj et al. [14] reported no false positivity by counter-current immuno-electrophoresis, but could detect only $25.2 \%$ of positive samples by this method. Tsang and Chau [15] conducted counter-current immuno-electrophoresis with three different antigens, i.e., Veronal buffer extract, ultrasonic lysate and protein antigen. They detected $98 \%$ positive and $10 \%$ false positive results with Veronal buffer extract, $96 \%$ positive and $32 \%$ false positive by ultrasonic lysate and $98 \%$ positive and $5 \%$ false positive by protein antigen.

Although serotyping is defined mainly by $\mathrm{O}$ and $\mathrm{H}$ antigens, other capsular antigens such as $\mathrm{A}, \mathrm{B}, \mathrm{M}$ and $\mathrm{Vi}$ have also been identified. In contrast to earlier studies the present study used relatively purified $\mathrm{O}, \mathrm{H}$ and $\mathrm{Vi}$ antigens to detect antibodies by counter-current immuno-electrophoresis in the patients' sera with confirmed and presumptive diagnosis to assess the sensitivity of this test.

Although no false positives were detected by $\mathrm{O}, \mathrm{H}$ and $\mathrm{Vi}$ antigens in the present study, positivity to $\mathrm{O}, \mathrm{H}$ and $\mathrm{Vi}$ antigens by counter-current immuno-electrophoresis was low. These results indicate high specificity but low sensitivity for counter-current immuno-electrophoresis. However, counter-current immuno-electrophoresis with $\mathrm{Vi}$ antigen was found to be more sensitive than with other antigens, as it could detect $50 \%$ of the patients in both the first and second groups. On the other hand, $\mathrm{H}$ antigen was found to be least sensitive as it was able to detect only $35 \%$ of the blood culture positive patients and, thus, appears to have little significant value in diagnosis. In patients where blood culture was positive, the positivity rate with any of the three antigens was only $59 \%$.

The failure to detect antibodies by counter-current immuno-electrophoresis and Widal agglutination in the blood culture positive typhoid patients can be due to the antibiotic treatment that most patients receive 
before coming to hospital for laboratory diagnosis. Pang and Puthucheary [16] also observed that antibiotic use may prevent the development of a rise in antibody titre.

Thus, the present findings indicate the need to develop a more sensitive, rapid and cost-effective method for the early diagnosis of typhoid fever. Although countercurrent immuno-electrophoresis with $\mathrm{O}, \mathrm{H}$ and $\mathrm{Vi}$ antigens of $S$. typhi has been found to be a highly specific and a quick test, because of its low sensitivity, either $\mathrm{Vi}$ antigen alone or a panel of three antigens could be used as an adjunct to diagnosis. Other methods such as DNA probes, or DNA or RNA amplification may be used in future for rapid and early diagnosis of the disease, but cost will remain a limiting factor. Therefore, there is an urgent need to develop cheaper methods such as second and third generation ELISAs which may be more suitable for routine testing.

\section{References}

1. Edelman R, Levine MM. Summary of an international workshop on typhoid fever. Rev Infect Dis 1986; 8: 329-349.

2. Stuart BM, Pullen RL. Typhoid: clinical analysis of three hundred and sixty cases. Arch Intern Med 1946; 78: 629-661.

3. Levine MM, Grados O, Gilman RH, Woodward WE, SolisPlaza R, Waldman W. Diagnostic value of the Widal test in areas endemic for typhoid fever. Am J Trop Med Hyg 1978; 27: $795-800$.
4. Gupta AK, Rao KM. Simultaneous detection of Salmonella typhi antigen and antibody in serum by counter-immunoelectrophoresis for an early and rapid diagnosis of typhoid fever. $J$ Immunol Methods 1979; 30: 349-353.

5. Ibrahim GF, Fleet GH, Lyons MJ, Walker RA. Method for the isolation of highly purified Salmonella flagellins. $J$ Clin Microbiol 1985; 22: 1040-1044.

6. Ewing WH (ed). The Genus Salmonella. In: Edwards and Ewing's Identification of Enterobacteriaceae, 4th edn. New York, Elsevier Science. 1986: 181-245.

7. Ouchterlony O, Nilsson LA. In: Weir DM (ed) Handbook of experimental immunology, vol I. Immunochemistry, 2nd edn. London, Blackwell. 1978: 19.

8. Keusch GT. Salmonellosis. In: Isselbacher KJ, Braunwald E, Wilson JD, Martin JB, Fauci AS, Kasper DL (eds) Harrison's Principles of internal medicine, 13 edn. New York, McGraw Hill. 1994: 621 .

9. Parker MT. Enteric infections: typhoid and paratyphoid fever In: Topley and Wilson's Principles of bacteriology, virology and immunity, vol 3. Bacterial diseases, 8th edn. London, Edward Arnold. 1990: 424-446.

10. Tsang RSW, Chau PY. Laboratory diagnosis of typhoid fever. In: Typhoid fever. Strategies for the 90 's. Singapore, World Scientific. 1992: 188.

11. Thompson KD, O'Keefe JP. Febrile agglutinins. Clin Microbiol Newslett 1987; 9: 128-130.

12. Akoh JA. Relative sensitivity of blood and bone marrow cultures in typhoid fever. Trop Doct 1991; 21: 174-176.

13. Duthie R, French GL. Comparison of methods for the diagnosis of typhoid fever. $J$ Clin Pathol 1990; 43: 863-865.

14. Sundararaj T, Ilango B, Subramanian S. A study on the usefulness of counter immuno-electrophoresis for the detection of Salmonella typhi antigen in the sera of suspected cases of enteric fever. Trans $R$ Soc Trop Med Hyg 1983; 77: 194-197.

15. Tsang RSW, Chau PY. Serological diagnosis of typhoid fever by counterimmunoelectrophoresis. BMJ 1981; 282 : 1505-1507.

16. Pang T, Puthucheary SD. Significance and value of the Widal test in the diagnosis of typhoid fever in an endemic area. $J$ Clin Pathol 1983; 36: 471-475. 